\title{
Simulasi Numerik Persamaan Transfer Panas Dua Dimensi Pada Silinder Komposit Multilayer dengan Sumber Panas Bergantung Waktu
}

\author{
Siti Alaa $^{1 *}$, Dian W. Kurniawidi ${ }^{1}$, Susi Rahayu ${ }^{1}$ \\ ${ }^{1}$ Program Studi Fisika, Universitas Mataram, Jl. Majapahit no. 62 Mataram, 83125 Indonesia. \\ *Email:siti.alaa@unram.ac.id
}

\section{A B S T R A C T}

Heat transfer is a physical phenomenon that is widely applied in the fields of aerospace, industrial, nuclear, power generation, and automotive. Simulations can be done to better understand the phenomenon of heat transfer in order to save costs and risks that arise. The heat transfer profile in a two-dimensional multilayered composite cylinder has been successfully determined using analytical and numerical methods. Temperature distribution profiles in different times and different thermal diffusivity for the two layers have been successfully calculated using Python 3.7 with the Numpy library.

Keywords: multilayered composite cylinder, numerical solution, heat transfer, Python.

\section{A B S T R A K}

Perpindahan panas merupakan fenomena fisika yang banyak diaplikasikan dalam bidang dirgantara, industri, nuklir, pembangkit listrik, dan otomotif. Simulasi dapat dilakukan untuk lebih memahami fenomena perpindahan panas agar dapat menghemat biaya dan risiko yang timbul. Profil perpindahan panas dalam silinder komposit multilayered dua dimensi telah berhasil ditentukan dengan menggunakan metode analitik dan numerik. Profil distribusi suhu dalam waktu yang berbeda dan difusivitas termal yang berbeda untuk dua lapisan telah berhasil dihitung menggunakan Python 3.7 dengan Numpy library.

Keywords: silinder multilayer komposit; simulasi numerik; perpindahan panas; Python

Diserahkan: 24-12-2019; Diterima: 30-12-2019;

Doi: https://doi.org/10.29303/emj.v1i2.44

\section{Pengantar}

Fenomena transfer panas banyak ditemukan di dunia industri seperti pada industri kimia, nuklir, dan pembangkit listrik (peniguel, 1998). Sehingga, pemahaman mendalam tentang fenomena ini sangat penting untuk kemajuan dalam desain peralatan atau untuk menjelaskan terjadinya kesalahan dalam peralatan tertentu. Dengan pemahaman ini pula, dapat dilakukan modifikasi peralatan sehingga tercapai standar keamanan dan efisiensi yang diinginkan.

Bahan/material komposit multilayer sendiri banyak digunakan di dunia industri. Hal ini disebabkan karena material komposit multilayer

* Corresponding author. 
mengkombinasikan sifat fisik, mekanik, dan termal dari bahan penyusun yang berbeda-beda.

Salah satu cara untuk memahami fenomena transfer panas adalah dengan menyelesaikan persamaan transfer panas. Dalira dan Noulazar (2014) telah mempelajari solusi analitik dari persamaan panas 3 dimensi pada silinder multilayer dengan menggunakan metode ekspansi fungsi eigen. Solusi analitik yang diberikan oleh Dalira dan Noulazar melibatkan fungsi trigonometri, kedua jenis fungsi Bessel, dan melibatkan deret tak-hingga. Hal ini menyebabkan sulitnya melakukan simulasi fenomena transfer panas untuk kasus-kasus spesifik.

Dalam paper ini, diberikan solusi numerik persamaan transfer panas dua dimensi pada silinder komposit multilayer. Solusi numerik didapatkan dengan menggunakan metode beda hingga. Lebih jauh, diberikan simulasi fenomena transfer panas untuk kasus material spesifik dengan memanfaatkan solusi numerik yang didapatkan sebelumnya menggunakan Python (Reitzle, 2019, and Cavazzuti, 2017) .

\section{Persamaan Transfer Panas dan Formulasi Solusi Numeriknya}

\subsection{Persamaan Transfer Panas}

Diberikan silinder komposit multilayer seperti pada gambar berikut.

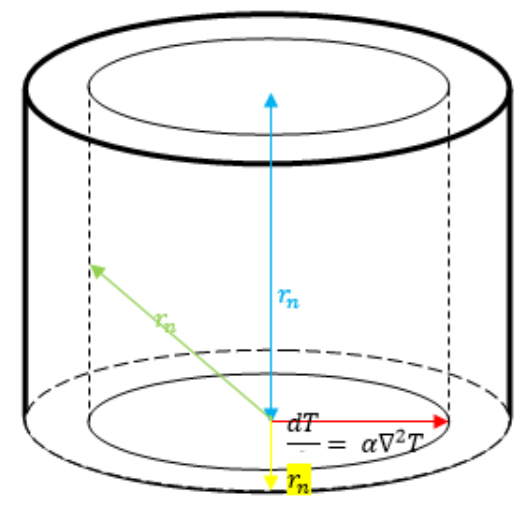

Gambar 1. Penampang silider komposit multilayer

Misalkan $\mathrm{T}$ adalah fungsi yang menunjukkan besarnya suhu pada silinder. Maka, bentuk umum persamaan transfer panas adalah sebagai berikut.

$$
\frac{d T}{d t}=\alpha \nabla^{2} T
$$

dengan

$$
\nabla^{2}=\frac{\partial^{2}}{\partial r^{2}}+\frac{1}{r} \frac{\partial}{\partial r}+\frac{1}{r^{2}} \frac{\partial^{2}}{\partial \theta^{2}}+\frac{\partial^{2}}{\partial z^{2}}
$$

dimana $\alpha$ merupakan suatu konstanta. Kemudian, misalkan sumbu-sumbu koordinat silinder adalah sebagai berikut.

$$
\begin{gathered}
r_{0} \leq r \leq r_{n} \\
0 \leq \theta \leq \varphi \\
0 \leq z \leq L
\end{gathered}
$$

dimana $r_{0}, \ldots, r_{n}$ adalah jari-jari dari masing-masing layer. Diasumsikan semua layer isotropik dan terjadi kontak panas sempurna antara dua layer berdekatan. Sehingga, persamaan transfer panas dalam bentuk koordinat silinder adalah sebagai berikut (Muzemdar, 2016).

$$
\frac{d T}{d t}=\alpha\left(\frac{1}{r} \frac{\partial}{\partial r}\left(r \frac{\partial T}{\partial r}\right)+\frac{1}{r^{2}} \frac{\partial^{2} T}{\partial \theta^{2}}+\frac{\partial^{2} T}{\partial z^{2}}\right)
$$

Saat $\mathrm{t}=0$, suhu pada layer ke-i adalah $f_{i}(r, \theta, z)$ dan saat $\mathrm{t}>0$, terdapat sumber panas $g_{i}(r, \theta, z, t)$. Sehingga, persamaan transfer panas pada silinder multilayer adalah sebagai berikut.

$$
\frac{1}{\alpha_{i}} \frac{\partial T_{i}}{\partial t}=\frac{\partial^{2} T_{i}}{\partial r^{2}}+\frac{1}{r} \frac{\partial T_{i}}{\partial r}+\frac{1}{r^{2}} \frac{\partial^{2} T_{i}}{\partial \theta^{2}}+\frac{\partial^{2} T_{i}}{\partial z^{2}}+\frac{g_{i}(r, \theta, z, t)}{k_{i}}
$$

dimana $k_{i}$ adalah suatu konstanta yang bergantung pada sifat termal dari material pada layer ke-i dan $T_{i}(r, \theta, z, t)$ merupakan suhu pada layer ke-i. Lebih jauh, asumsikan bahwa batas-batas variabel seperti berikut.

$$
\begin{gathered}
r_{0} \leq r \leq r_{n} \\
r_{i-1} \leq r \leq r_{i} \\
0 \leq \theta \leq \varphi \\
\varphi \leq 2 \pi \\
0 \leq z \leq L \\
t \geq 0
\end{gathered}
$$

Kondisi batas berikut juga diasumsikan terpenuhi.

$$
A_{i n} \frac{\partial T_{i}}{\partial r}\left(r_{0}, \theta, z, t\right)+B_{i n} T_{i}\left(r_{0}, \theta, z, t\right)=C_{i n}
$$

$$
A_{\text {out }} \frac{\partial T_{n}}{\partial r}\left(r_{n}, \theta, z, t\right)+B_{\text {out }} T_{n}\left(r_{0}, \theta, z, t\right)=C_{\text {out }}
$$


dimana $A_{\text {in }}, B_{\text {in }}$, dan $C_{\text {in }}$ adalah koefisien untuk bidang batas bagian dalam serta $A_{\text {out }}, B_{\text {out }}$, dan $C_{\text {out }}$ adalah koefisien untuk bidang batas bagian luar. Kemudian, saat $\theta=0$, maka $T_{i}(r, 0, z, t)=0$ atau $\frac{\partial T_{i}}{\partial \theta}(r, 0, z, t)=0 . \quad$ Saat $\quad \theta=\varphi, \quad$ maka $T_{i}(r, \varphi, z, t)=0$ atau $\frac{\partial T_{i}}{\partial \theta}(r, \varphi, z, t)=0$.

\subsection{Solusi Numerik Persamaan Transfer}

\section{Panas}

Pada bagian ini, diuraikan formulasi solusi numerik persamaan transfer panas dengan menggunakan metode beda hingga.

Dengan menggunakan ekspansi deret Taylor pada persamaan transfer panas di layer ke-i, diperoleh.

$T_{i}(x, t+\Delta t)=T_{i}(x, t)+\frac{\partial T_{i}}{\partial t} \Delta t+\frac{\partial^{2} T_{i}}{\partial t^{2}} \frac{\Delta t^{2}}{2 !}+$ $\frac{\partial^{3} T_{i}}{\partial t^{3}} \frac{\Delta t^{3}}{3 !}+\cdots$

$$
\begin{gathered}
=T_{i}(x, t)+\frac{\partial T_{i}}{\partial t} \Delta t+\frac{\partial^{2} T_{i}}{\partial t^{2}} \frac{\Delta t^{2}}{2}+\frac{\partial^{3} T_{i}}{\partial t^{3}} \frac{\Delta t^{3}}{6}+\cdots \\
\ldots+\frac{\partial^{n} T_{i}}{\partial t^{n}} \frac{\Delta t^{n}}{n !}
\end{gathered}
$$

Sehingga, diperoleh

$\frac{\partial T_{i}}{\partial t} \Delta t=T_{i}(r, \theta, z, t+\Delta t)-T_{i}(r, \theta, z, t)$

atau

$$
\frac{\partial T_{i}}{\partial t}=\frac{T_{i}(r, \theta, z, t+\Delta t)-T_{i}(r, \theta, z, t)}{\Delta t}
$$

Dengan cara serupa terhadap $r$, diperoleh juga persamaan berikut

$$
\begin{aligned}
& T_{i}(r+\Delta r, \theta, z, t)=T_{i}(r, \theta, z, t)+\frac{\partial T_{i}}{\partial r} \Delta r+\frac{\partial^{2} T_{i}}{\partial r^{2}} \frac{\Delta r^{2}}{2 !} \\
& +\frac{\partial^{3} T_{i}}{\partial r^{3}} \frac{\Delta r^{3}}{3 !}+\cdots \\
& =T_{i}(r, \theta, z, t)+\frac{\partial T_{i}}{\partial r} \Delta r+\frac{\partial^{2} T_{i}}{\partial r^{2}} \frac{\Delta r^{2}}{2} \\
& \quad+\frac{\partial^{3} T_{i}}{\partial r^{3}} \frac{\Delta r^{3}}{6}+\vartheta\left(\Delta r^{4}\right)
\end{aligned}
$$

dan

$$
T_{i}(r-\Delta r, \theta, z, t)=T_{i}(r, \theta, z, t)-\frac{\partial T_{i}}{\partial r} \Delta r+\frac{\partial^{2} T_{i}}{\partial r^{2}} \frac{\Delta r^{2}}{2 !}
$$

$$
\begin{aligned}
& -\frac{\partial^{3} T_{i}}{\partial r^{3}} \frac{\Delta r^{3}}{3 !}+\cdots \\
& =T_{i}(r, \theta, z, t)-\frac{\partial T_{i}}{\partial r} \Delta r+\frac{\partial^{2} T_{i}}{\partial r^{2}} \frac{\Delta r^{2}}{2} \\
& -\frac{\partial^{3} T_{i}}{\partial r^{3}} \frac{\Delta r^{3}}{6}+\vartheta\left(\Delta r^{4}\right) .
\end{aligned}
$$

Sehingga, diperoleh

$$
\begin{aligned}
& \frac{\partial^{2} T_{i}}{\partial r^{2}}+\vartheta\left(\Delta r^{4}\right) \\
& =\frac{T_{i}(r+\Delta r, \theta, z, t)-2 T_{i}(r, \theta, z, t)+T_{i}(r-\Delta r, \theta, z, t)}{\Delta r^{2}}
\end{aligned}
$$

Dengan menggunakan hampiran, didapatkan

$$
\frac{\partial^{2} T_{i}}{\partial r^{2}} \approx \frac{T_{i}(r+\Delta r, \theta, z, t)-2 T_{i}(r, \theta, z, t)+T_{i}(r-\Delta r, \theta, z, t)}{\Delta r^{2}}
$$

Dengan cara serupa, didapatkan pula persamaan hampiran turunan terhadap $\theta$ dan $\mathrm{z}$ sebagai berikut.

$$
\frac{\partial^{2} T_{i}}{\partial \theta^{2}}=\frac{T_{i}(r, \theta+\Delta \theta, z, t)-2 T_{i}(r, \theta, z, t)+T_{i}(r, \theta-\Delta \theta, z, t)}{\Delta \theta^{2}}
$$

dan

$$
\frac{\partial^{2} T_{i}}{\partial z^{2}}=\frac{T_{i}(r, \theta, z+\Delta z, t)-2 T_{i}(r, \theta, z, t)+T_{i}(r, \theta, z-\Delta z, t)}{\Delta z^{2}}
$$

Untuk kepentingan simulasi, dimisalkan salah satu sumbu koordinat adalah fiks. Saat variabel z fiks, maka diperoleh $\frac{\partial T_{i}}{\partial z}=0$ dan $\frac{\partial^{2} T_{i}}{\partial^{2} z}=0$. Misalkan 1,m,

dan $\mathrm{n}$ berturut-turut merupakan indeks diskrit untuk variabel $r, t$, dan $\theta$. Maka, diperoleh persamaanpersamaan berikut.

$$
\begin{gathered}
\frac{\partial T_{i}}{\partial t}=\frac{T^{i}(l, n, m+1)-T^{i}(l, n, m)}{\Delta t} \\
\frac{\partial T_{i}}{\partial r}=\frac{T^{i}(l+1, n, m)-T^{i}(l, n, m)}{\Delta r} \\
\frac{\partial^{2} T_{i}}{\partial r^{2}}=\frac{T^{i}(l+1, n, m)-2 T^{i}(l, n, m)+T^{i}(l-1, n, m)}{\Delta r^{2}} \\
\frac{\partial^{2} T_{i}}{\partial \theta^{2}}=\frac{T^{i}(l, n+1, m)-2 T^{i}(l, n, m)+T^{i}(l, n-1, m)}{\Delta \theta^{2}}
\end{gathered}
$$

Sehingga, solusi numerik persamaan transfer panas dua dimensi (saat variabel $\mathrm{z}$ fiks) pada layer ke-i di silinder komposit adalah

$$
T_{l, n, m+1}^{i}=T_{l, n, m}^{i}+\frac{\alpha_{i} \Delta t}{\Delta r^{2}}\left(T_{l+1, n, m}^{i}-2 T_{l, n, m}^{i}+T_{l-1, n, m}^{i}\right)
$$

$$
+\frac{\alpha_{i} \Delta t}{r_{l} \Delta r}\left(T_{l+1, n, m}^{i}-T_{l, n, m}^{i}\right)
$$




$$
\begin{gathered}
+\frac{\alpha_{i} \Delta t}{r_{l}^{2} \Delta \theta^{2}}\left(T_{l, n+1, m}^{i}-2 T_{l, n, m}^{i}+T_{l, n-1, m}^{i}\right) \\
+\frac{\alpha_{i} \Delta t}{l_{i}} g_{i}\left(r_{n}, \theta_{m}, z, t_{l}\right) .
\end{gathered}
$$

\section{Simulasi}

Solusi numerik kemudian disimulasikan menggunakan Python 3.7. dengan asumsi tambahan bahwa sumber panas konstan terhadap waktu.

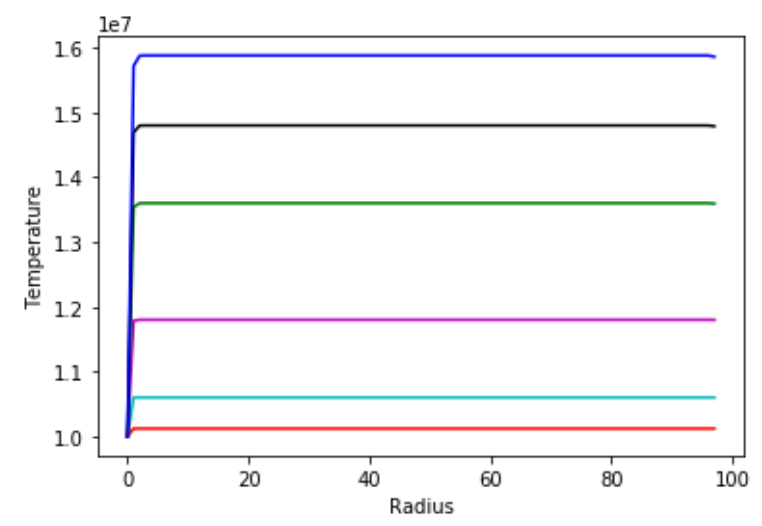

Gambar 2. Distribusi suhu untuk waktu yang berbeda pada lapisan pertama dengan $\alpha=1,1 \cdot 10^{-3}$

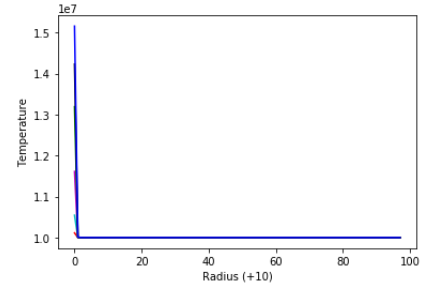

(a)

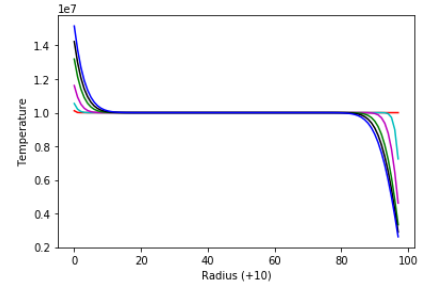

(c)

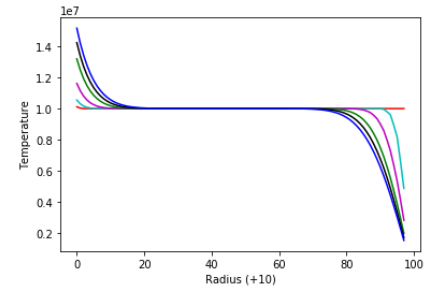

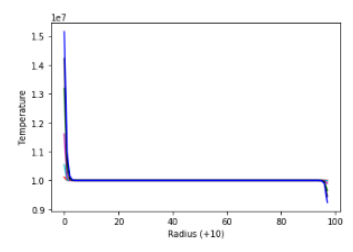

(b)

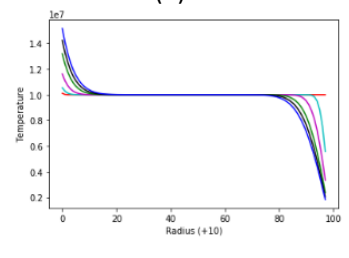

(d) $: t=2$ $: t=10$ $: t=30$

$: t=60$

$: t=80$

$: t=98$ (e)

Gambar 3. Distribusi suhu pada lapisan kedua pada berbagai nilai , (a) $\alpha=1.1 \times 10^{-4}$, (b) $\alpha=$ $1.1 \times 10^{-2}, \quad$ (c) $\quad \alpha=1.1 \times 10^{-0.5}, \quad$ (d) $\alpha=$
$1.1 \times 10^{-0.2}$, (e) $\alpha=1.1 \times 10^{-0.05}$

Gambar 2 menunjukkan profil suhu untuk lapisan pertama. Seperti yang bisa kita lihat, suhu meningkat seiring waktu. Ini karena sumber panas konstan dan panas dikirim melalui silinder dan memenuhi profil suhu dalam kondisi batas dari lapisan kedua.

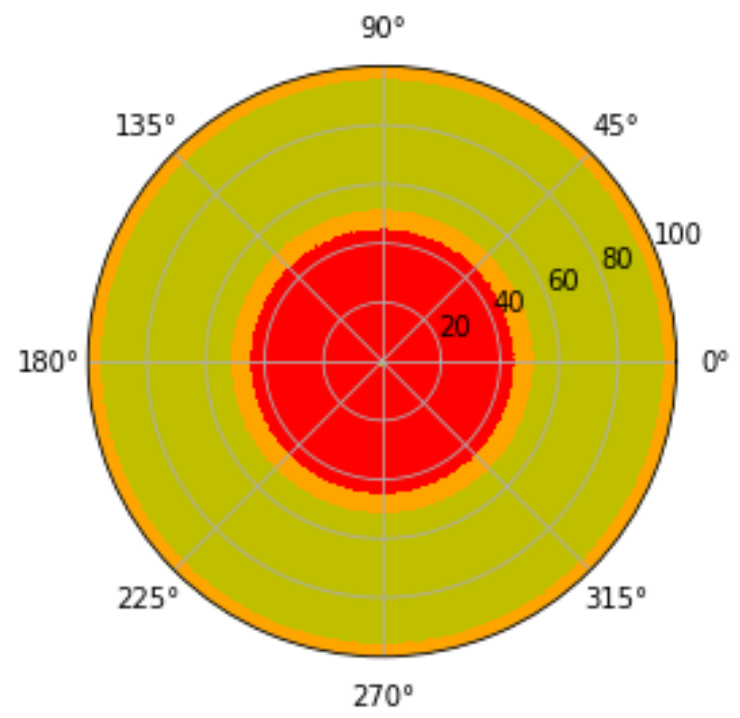

Gambar 4. Distribusi suhu pada silinder dengan dua lapisan yang berbeda. Nampak perubahan suhu pada bidang batas antar dua lapisan.

Ketika panas dikirim ke lapisan kedua, suhu menurun seperti yang ditunjukkan pada Gambar 3, dan gradien negatif kurva tergantung pada difusivitas termal $(\alpha)$ medium. Sedangkan Gambar 4 menunjukkan profil suhu pada waktu tertentu untuk semua $\mathrm{r}$ dan $\theta$.

\section{Kesimpulan}

Profil perpindahan panas dalam silinder komposit multilayered dua dimensi telah berhasil ditentukan dengan menggunakan metode analitik dan numerik. Profil distribusi suhu dalam waktu yang berbeda dan difusivitas termal yang berbeda untuk dua lapisan telah berhasil dihitung menggunakan Python 3.7.

\section{Ucapan terima kasih}


Penelitian ini didanai oleh dana PNBP Universitas Mataram Tahun Anggaran 2019.

\section{DAFTAR PUSTAKA}

C. Peniguel. (1998). Heat transfer simulation for industrial applications: needs, limitations, expectations. International journal of heat and fluid flow. Volume 19, issue 2, pages 102-114

Cavazzuti, M., \& Corticelli, M. A. (2017). An algorithm for solving steady-state heat conduction in arbitrarily complex composite planar walls with temperature-dependent thermal conductivities. Applied Thermal Engineering, $115, \quad 825-831$. doi:10.1016/j.applthermaleng.2017.01.030

N. Dalira and s. S. Nourazar. (2014). Analytical solution of the problem on the threedimensional transient heat conduction in a multilayer cylinder. Journal of Engineering Physics and Thermophysics, Vol. 87, No. 1

Reitzle, D., Geiger, S., \& Kienle, A. (2019). Semianalytical solution of the time-dependent heat equation for three-dimensional anisotropic multi-layered media. International Journal of Heat and Mass Transfer, 134, 984-992. doi:10.1016/j.ijheatmasstransfer.2018.12.174

Sandip Mazumder. (2016). Numerical Methods for Partial Differential Equations. Elsevier, USA. 